\title{
EFEITO DO CONDICIONAMENTO OSMÓTICO NO VIGOR DE PLÂNTULAS DE FEIJÃO (Phaseolus vulgaris L.) ${ }^{1}$
}

\author{
Messias Firmino de Queiroz ${ }^{2}$, Francisco de Assis Cardoso Almeida ${ }^{3}$ \\ e Pedro Dantas Fernandes ${ }^{3}$
}

\begin{abstract}
RESUMO
Estudou-se o efeito de seis níveis de potencial osmótico (0, -0,2 -0,4 -0,6-0,8 e -1,0MPa) induzidos por polietileno glicol-6000 (PEG-6000) sobre o vigor de sementes de dez cultivares de feijão (Phaseolus vulgaris, L.). O experimento foi conduzido em laboratório, em condições de temperatura e umidade controladas e substrato de papel-toalha e o delineamento experimental foi o inteiramente casualizado, em esquema fatorial de 10 x 6, com 4 repetições, cada uma com dez sementes. Houve avaliação do comprimento médio da radícula, do comprimento médio do hipocótilo e da relação radícula/hipocótilo. A medição das plântulas foi realizada em todas as cultivares, para cada nível de PEG-6000, no momento em que uma das dez cultivares atingia o nível de $80 \%$ de germinação, ou tivessem decorridos 20 dias da instalação do teste, estando as plântulas com hipocótilo e radícula nitidamente diferenciados, com comprimento mínimo de $0,5 \mathrm{~cm}$. Pelos resultados obtidos, verificou-se haver influência do PEG-6000 sobre o vigor das plântulas. A cv. Diamante Negro foi a mais vigorosa em baixos potenciais osmóticos (-0,4MPa e -0,6MPa) e a Safira, a mais sensível. Sob condições de estresse hídrico, as radículas tenderam a se alongar mais que o hipocótilo e os genótipos menos tolerantes desenvolveram maior relação radícula/hipocótilo.
\end{abstract}

Palavras-chave: PEG-6000, potencial osmótico, relação radícula/hipocótilo, sementes

\section{OSMOTIC CONDITIONING EFFECT ON VIGOUR OF BEAN (Phaseolus vulgaris L.) SEEDLINGS}

\begin{abstract}
The objective of this work was to study the effect of six levels of osmotic potential $(0,-0.2,-0.4,-0.6$, -0.8 and $-1 \mathrm{MPa}$ ), induced by polyetilene glycol 6000 (PEG-6000), on the vigour of seed germination of ten bean cultivars (Phaseolus vulgaris, L.). The experiment was conducted in laboratory under controlled conditions of temperature and humidity, using paper towels as a substract. The experimental design was completely randomized in a $10 \times 6$ factorial scheme with four replications each consisting of 10 seeds. The growth of radicle and hypocotyl as well as the radicle/hypocotyl relation were evaluated. The measurement of seedlings was made in all cultivars, for each level of PEG-6000, when one of ten cultivars reached the $80 \%$ germination or after 20 days elapsed from the beginning of the test, with seedling showing the hypocotyl and the radicle well differentiated, with a minimum length of $0.5 \mathrm{~cm}$. The results obtained have shown that there was influence of PEG-6000 on the seedlings' vigour. 'Diamante Negro' was found to be the most vigourous cultivar under reduced osmotic potential (-0.4MPa and -0.6 $\mathrm{MPa})$, while 'Safira' was the most sensitive one. In water stress conditions radicles tended to be longer than the hypocotyl, and the less tolerant genotypes developed higher radicle/hypocotyl relations.
\end{abstract}

Key words: PEG-6000, osmotic potential, radicle/hypocotyl relation, seed

\footnotetext{
${ }^{1}$ Parte da Dissertação de Mestrado do primeiro autor

${ }^{2}$ Engenheiro Agrônomo, Professor Visitante da UEPB, CEP 58117-000, Lagoa Seca, PB. E-mail: mqueiroz@ paqtc.rpp.br

${ }^{3}$ Professor Doutor, Departamento Engenharia Agrícola/CCT/UFPB, Av. Aprígio Veloso 882, CP 10087, CEP 58109-970,

Campina Grande, PB, Brasil. E-mail: copeag@deag.ufpb.br
} 


\section{INTRODUÇÃO}

O feijão é um dos principais alimentos do brasileiro, sendo consumidos, anualmente, cerca de 3,25 milhões de toneladas em todo o país (Zimmermann et al. 1988). Devido à sua importância, pesquisadores se empenham em melhorar a produtividade e a qualidade das variedades cultivadas no Brasil.

A atenção dos estudiosos começa com a semente, sendo o vigor uma das principais características de investigação, por se tratar de um importante componente de avaliação de sua qualidade (Popinigis, 1977).

O conceito de vigor pode ser considerado, primeiramente, como potencial máximo para o estabelecimento de plântulas e, em segundo lugar, como a diminuição potencial daquele máximo, até ocorrer a morte da semente, isto é, até atingir um potencial de estabelecimento igual a zero. O máximo é fixado pela constituição genética da planta e, normalmente, é característico de cada população de sementes (Pollock \& Ross, 1972).

O nível de vigor das sementes influi decisivamente sobre o processo de germinação, quer retardando-o, provocando o aparecimento de plântulas anormais, quer impedindo a germinação. Heydecker (1972) afirma que o vigor está condicionado a uma ampla limitação das condições ambientais, incluindo situações de estresse.

Freqüentemente são utilizados testes de vigor, em meio osmótico, para se avaliar a tolerância ao déficit hídrico de espécies vegetais, tendo sido encontradas altas correlações entre parâmetros de vigor e produtividade (Popinigis, 1977). Franco et al. (1993) por exemplo, trabalhando com melão em diferentes potenciais osmóticos, observaram que a velocidade de crescimento inicial da raiz primária correlacionava-se positivamente com o rendimento da cultura.

Segundo Villela et al. (1991), a presença de solutos altera as propriedades da água, resultando numa pressão osmótica diferente de zero na solução. No condicionamento osmótico o soluto mais utilizado tem sido o polietileno glicol-6000, cuja fórmula é $\mathrm{HOCH}_{2}\left(\mathrm{CH}_{2} \mathrm{OCH}_{2}\right)_{\mathrm{n}} \mathrm{CH}_{2} \mathrm{OH}$, por ser quimicamente inerte e não apresentar toxicidade sobre as sementes.

Estudou-se, no presente trabalho, o efeito de seis níveis de potencial osmótico, obtidos a partir de diferentes concentrações de polietileno glicol-6000, sobre o vigor de dez cultivares de feijão (Phaseolus vulgaris L.), identificando-se as mais tolerantes e as mais sensíveis ao déficit hídrico.

\section{MATERIAL E MÉTODOS}

Em trabalho conduzido no Laboratório de Sementes da Embrapa Algodão, em Campina Grande, PB, no período de abril a junho de 1995, foram estudados dois fatores: cultivares de feijão (C) e níveis de potencial osmótico (N). O fator cultivar constou de 10 genótipos de feijão (Phaseolus vulgaris, L.), cedidos pelo CNPAF - EMBRAPA, com sede em Goiânia, GO, a seguir relacionados: $\mathrm{C}_{1}-\mathrm{A} 285 ; \mathrm{C}_{2}-$ Safira $\mathrm{C}_{3}$ - Diamante Negro; $\mathrm{C}_{4}$ - São José; $\mathrm{C}_{5}$ - Corrente; $\mathrm{C}_{6}$ - Goytacazes; $\mathrm{C}_{7}$ - Novo Jalo; $\mathrm{C}_{8}$ - Jalo Precoce; $\mathrm{C}_{9}$ - Xamego e $\mathrm{C}_{10}$ - Onix. Encontram-se, na Tabela 1, as concentrações de polietileno glicol-6000 (PEG6000) e respectivos níveis de potencial osmótico resultantes, preparados segundo recomendações de Villela et al. (1991).
Tabela 1. Relação das soluções de PEG-6000 para obtenção dos diferentes potenciais osmóticos

\begin{tabular}{ccc}
\hline $\begin{array}{c}\text { Solução } \\
(\mathrm{N})\end{array}$ & $\begin{array}{c}\text { Concentração } \\
\text { (gramas de PEG.kg }\end{array}$ & $\begin{array}{c}\text { Potencial Osmotico } \\
(\mathrm{MPa}) .\end{array}$ \\
\hline $\mathrm{N}_{1}$ & 0,00 & 0,0 \\
$\mathrm{~N}_{2}$ & 119,571 & $-0,2$ \\
$\mathrm{~N}_{3}$ & 178,343 & $-0,4$ \\
$\mathrm{~N}_{4}$ & 223,664 & $-0,6$ \\
$\mathrm{~N}_{5}$ & 261,948 & $-0,8$ \\
$\mathrm{~N}_{6}$ & 295,713 & $-1,0$ \\
\hline
\end{tabular}

Os testes de vigor foram realizados em germinador de prateleiras horizontais com controle automático de temperatura para $25^{\circ} \mathrm{C}$ e sensibilidade de $\pm 0,5^{\circ} \mathrm{C}$. A umidade relativa no interior do germinador foi mantida próximo à saturação, com sistema próprio de circulação de água e ar. Houve avaliação do comprimento de radícula, do comprimento de hipocótilo e da relação radícula/hipocótilo, segundo metodologia contida em Vieira \& Carvalho (1994). O tempo de duração dos testes variou de acordo com os níveis de PEG-6000, por tratar-se de simulação de déficit hídrico, que retarda a germinação das sementes. A avaliação ocorreu no momento em que era atingido o nível de $80 \%$ de germinação em cada tratamento, esperando-se o máximo de 20 dias, considerando-se como germinadas as sementes que desenvolviam plântulas com radícula e hipocótilo nitidamente diferenciados, com comprimento mínimo de $0,5 \mathrm{~cm}$. Considerando-se esses critérios, o tratamento $\mathrm{N}_{1}$ foi avaliado no $5^{\circ}$ dia, $\mathrm{N}_{2}$ no $8^{\circ}$ dia, $\mathrm{N}_{3}$ no $11^{\circ}$ dia e, a partir de $\mathrm{N}_{4}$, no $20^{\circ}$ dia.

$\mathrm{O}$ delineamento experimental adotado foi o inteiramente casualizado, em esquema fatorial 10x6, com 4 repetições, 10 sementes por repetição (Popinigis, 1977) processando-se as análises estatísticas e de regressão polinominal, segundo orientações de Snedecor \& Cochran (1974) e Gomes (1985).

\section{RESULTADOS E DISCUSSÃO}

$\mathrm{Na}$ análise estatística foi observado efeito interativo entre os fatores estudados. Os níveis de potencial osmótico afetaram o comprimento da radícula e do hipocótilo de modo diferenciado entre as cultivares.

\section{Comprimento de radícula}

Os resultados de comprimento de radícula encontram-se representados graficamente na Figura 1. Pelas equações obtidas, observa-se que o comprimento da radícula de cada cultivar variou em função da concentração de PEG-6000. A partir de - $0,2 \mathrm{MPa}\left(\mathrm{N}_{2}\right)$ ocorreu redução acentuada da radícula, atingindo o valor zero no potencial de $-0,8 \mathrm{MPa}$, isto é, nesses níveis não houve emergência de raízes. Os baixos potenciais osmóticos simulados por PEG-6000 no substrato restringiram a absorção de água pela semente, provocando estresse hídrico e, consequentemente, inibindo o alongamento da radícula, fato igualmente observado em feijão por Prisco \& O'Leary (1970).

Para melhor interpretação dos resultados, as médias dos tratamentos para cada cultivar foram comparadas às da testemunha $\left(\mathrm{N}_{1}\right)$ obtendo-se os valores contidos na Tabela 2. Em geral, verifica-se serem muito sensíveis todas as cultivares 
em baixos potenciais osmóticos, não havendo emissão de raízes a partir de -0,8MPa. Prisco \& O'Leary (1970) e Magalhães \& Carelli (1972) também verificaram alta sensibilidade do feijão em baixos potenciais induzidos com PEG.
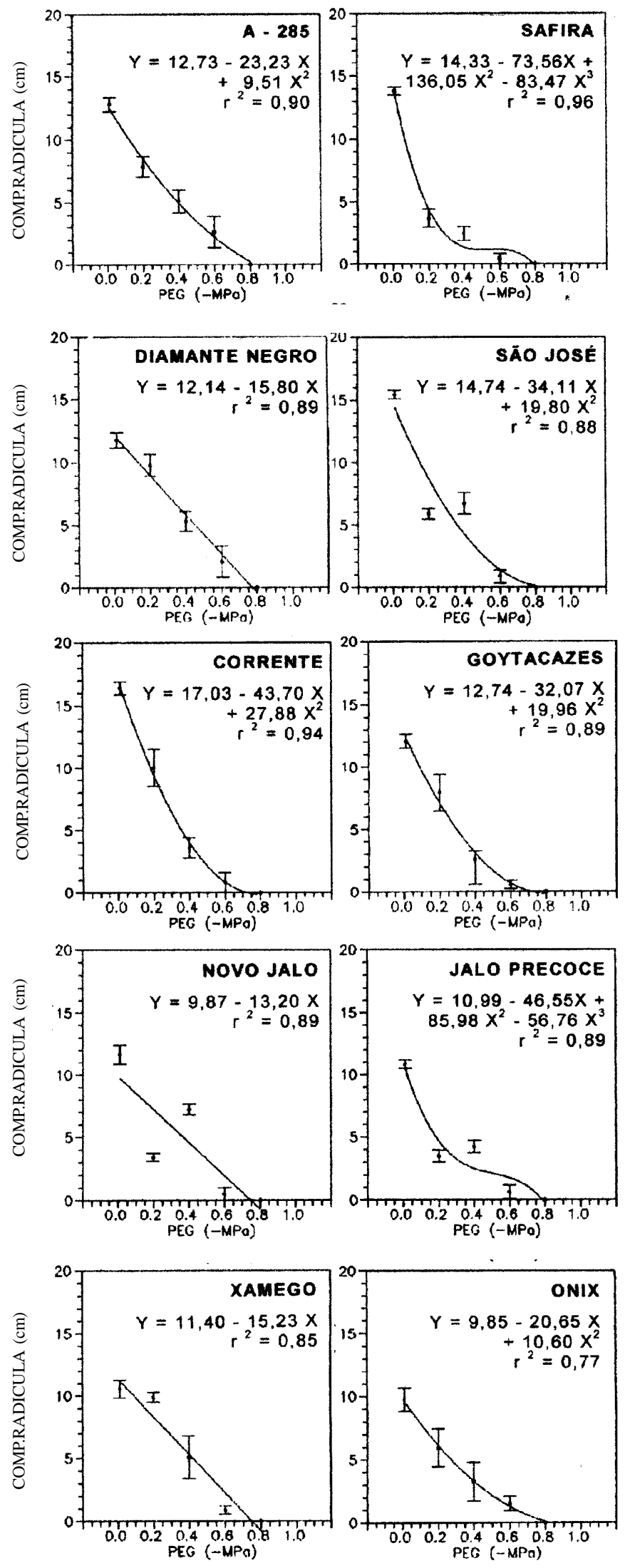

Figura 1. Índice de vigor (comprimento de radícula) das cultivares de feijão, em função dos níveis de concentração de PEG-6000.
Tabela 2. Redução relativa* do comprimento da radícula em comparação à testemunha $\left(\mathrm{N}_{1}\right)$ segundo os níveis de PEG6000 para cada uma das cultivares de feijão

\begin{tabular}{lccccc}
\hline & \multicolumn{5}{c}{ Redução relativa (\%) } \\
\cline { 2 - 6 } \multicolumn{1}{c}{ Cultivares relação à testemunha $\left(\mathrm{N}_{1}\right)$} \\
\cline { 2 - 6 } & $\mathrm{N}_{2}$ & $\mathrm{~N}_{3}$ & $\mathrm{~N}_{4}$ & $\mathrm{~N}_{5}{ }^{* *}$ & $\mathrm{~N}_{6}{ }^{* *}$ \\
\hline 1. A285 & $8^{\circ}$ & $11^{\circ}$ & $20^{\circ}$ & $20^{\circ}$ & $20^{\circ}$ \\
2. Safira & 38,7 & 60,1 & 79,4 & - & - \\
3. Diamante Negro & 16,8 & 54,9 & 82,4 & - & - \\
4. São José & 61,8 & 56,6 & 94,2 & - & - \\
5. Corrente & 38,8 & 78,1 & 94,9 & - & - \\
6. Goytacazes & 34,1 & 78,7 & 95,3 & - & - \\
7. Novo Jalo & 70,8 & 38,0 & 95,8 & - & - \\
8. Jalo Precoce & 68,0 & 61,1 & 94,4 & - & - \\
9. Xamego & 6,2 & 51,8 & 91,8 & - & - \\
10. Onix & 39,1 & 66,7 & 94,2 & - & - \\
\hline
\end{tabular}

** Não houve germinação

* Redução Relativa $(\%)=1-\frac{\text { comp. de radícula de uma cv em um nível de PEG-6000 }}{\text { comprimento de radícula da mesma cv. na testemunha }} \times 100$

A cv. Safira foi a mais afetada, com redução no comprimento de radícula da ordem de 73,64, 82,40 e 96,96\%, nos níveis N2, N3 e N4, respectivamente; muito sensíveis foram, também, os genótipos Novo Jalo, Jalo Precoce e São José, já no tratamento $\mathrm{N}_{2}$, correspondente a -0,2MPa. Por sua vez, Diamante Negro, A-285 e Xamego foram as menos afetadas nesses mesmos níveis de estresse hídrico. Campos \& Assunção (1990) observaram, também, trabalhando com arroz, redução do comprimento da radícula em soluções mais concentradas de PEG-6000.

Esses resultados levam a crer que as diferenças observadas entre as cultivares, nos vários níveis de concentração de PEG-6000, devem estar ligadas à constituição genética de cada genótipo. Carvalho e Nakagawa (1980) citam que as diferenças entre linhagens ou cultivares são resultantes do vigor genético, enquanto o vigor fisiológico é observado entre lotes de uma mesma linhagem ou cultivar.

\section{Comprimento de hipocótilo}

Observa-se, na Figura 2, que o comprimento do hipocótilo e os níveis de concentração de PEG-6000 estão associados, significativa e diferentemente, dependendo da cultivar, expressos em equações polinomiais com alto grau de correlação.

As cultivares Jalo Precoce, Novo Jalo e Safira foram as mais sensíveis, seguidas da São José, com crescimento muito pequeno do hipocótilo, mesmo em condições de pouco estresse hídrico (-0,2MPa). Melhor interpretação e discussão dos dados é possível através da comparação de cada nível com a testemunha, obtendo-se a redução relativa, conforme apresentado na Tabela 3 .

A partir de -0,4MPa, o efeito sobre o hipocótilo foi ainda mais drástico, reduzindo-o em mais de $70 \%$, atingindo $100 \%$ nos níveis $-0,8 \mathrm{MPa}$ e $-1,0 \mathrm{MPa}$, em que não houve germinação de sementes das cultivares estudadas.

Observa-se que entre a testemunha $\left(\mathrm{N}_{1}\right)$ e o nível $\mathrm{N}_{2}$, as cultivares Jalo Precoce, Novo Jalo e Safira tiveram as maiores reduções médias de comprimento de hipocótilo, superiores a $89 \%$, denotando-se o seu baixo vigor neste nível de estresse 
hídrico simulado; da mesma forma, Xamego, Diamante Negro e Corrente foram as mais vigorosas em comprimento médio de hipocótilo, pois tiveram as menores reduções $(39,2,44,85$ e $48,30 \%$, respectivamente).

Ressalte-se que essas diferenças resultaram diretamente do
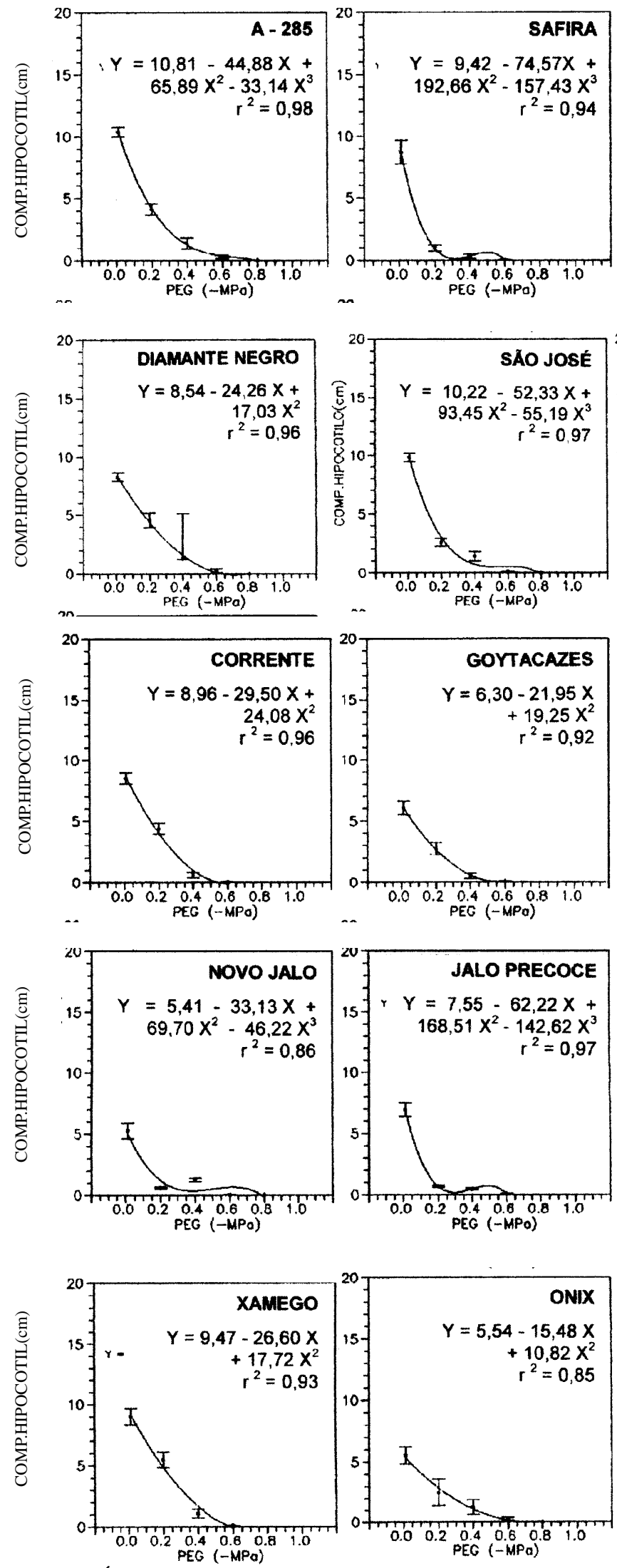

Figura 2. Índice de vigor (comprimento de hipocótilo) das cultivares de feijão, em função dos níveis de concentração de PEG-6000.
Tabela 3. Redução relativa* do comprimento do hipocótilo, em relação à testemunha, em função dos níveis de PEG-6000 para cada uma das cultivares de feijão

\begin{tabular}{lccccc}
\hline \multirow{2}{*}{ Cultivares } & \multicolumn{5}{c}{ Redução relativa (\%) em relação à testemunha ( $\left.\mathrm{N}_{1}\right)$} \\
\cline { 2 - 6 } & $\mathrm{N}_{2}$ & $\mathrm{~N}_{3}$ & $\mathrm{~N}_{4}$ & $\mathrm{~N}_{5}$ & $\mathrm{~N}_{6}$ \\
\hline \multirow{5}{*}{ Dia em que foi feita a avaliação } \\
1. A 285 & $8^{\circ}$ & $11^{\circ}$ & $20^{\circ}$ & $20^{\circ}$ & $20^{\circ}$ \\
2. Safira & 60,4 & 86,8 & 97,2 & - & - \\
3. Diamante Negro & 44,8 & 84,0 & 97,0 & - & - \\
4. São José & 73,8 & 85,8 & 99,1 & - & - \\
5. Corrente & 48,3 & 92,6 & 99,4 & - & - \\
6. Goytacazes & 54,8 & 91,1 & 98,7 & - & - \\
7. Novo Jalo & 89,1 & 75,8 & 99,4 & - & - \\
8. Jalo Precoce & 90,0 & 93,1 & 99,1 & - & - \\
9. Xamego & 39,2 & 88,0 & 99,0 & - & - \\
0. Onix & 54,7 & 77,1 & 95,7 & - & - \\
** Não houve germinação & comp. de hip. p/ uma cv. em um nível de PEG-6000 & \\
\cline { 2 - 6 } * Redução Relativa (\%) $=100$ & comp. de hipocótilo da mesma cv. na testemunha
\end{tabular}

estresse hídrico simulado pelo aumento das concentrações osmóticas de PEG-6000, concordando com observações de Magalhães \& Carelli (1972) e de Machado et al. (1976) em feijão e de Parmer \& Moore (1968) em milho. Efeitos similares foram encontrados em Raphanus sativus, L. (Fernandez \& Johnston, 1978), em Zea mays L. (Singh \& Singh, 1981) e Triticum aestivum L. (Singh \& Singh, 1982).

Observa-se, ainda na Tabela 3, que no nível $\mathrm{N}_{3}$ a maior redução relativa do comprimento do hipocótilo ocorreu na cultivar Safira (>96\%). Os genótipos Jalo Precoce, Corrente e Goytacazes apresentaram, também, comprimento de hipocótilo bastante reduzido (>90\%) em relação à testemunha.

\section{Relação radícula/hipocótilo}

Os resultados da relação radícula/hipocótilo do teste de vigor das dez cultivares de feijão encontram-se na Tabela 4; em geral, tal relação aumentou na medida em que se elevaram as concentrações dos níveis de PEG-6000. Em todas as cultivares, os valores médios de comprimento de radícula foram sempre superiores aos de comprimento de hipocótilo nos seis níveis de PEG-6000 e tanto a radícula como o hipocótilo reduziram-se, sendo que tal redução foi sempre maior para a parte aérea (hipocótilo); portanto, em condições de estresse hídrico durante a fase germinativa do feijoeiro, as raízes tendem a se desenvolver mais que o hipocótilo, como forma de defesa contra as condições adversas do meio e necessidade de absorver mais água para crescimento e desenvolvimento da plântula. Estas observações estão de acordo com descrições da literatura sobre o assunto (Kramer, 1969; Slayter, 1969).

Observa-se que, em geral, os genótipos menos tolerantes ao estresse hídrico tiveram maior relação radícula/hipocótilo. A cv. Safira que, pelos dados apresentados anteriormente foi uma das menos vigorosas, desenvolveu maior relação radícula/parte aérea que a cv. Diamante Negro, classificada entre as de maior vigor. Sugere-se que, quando uma cultivar mais sensível é submetida a estresse hídrico, terá que despender mais energia na absorção de água para a sua sobrevivência, resultando em maior crescimento do sistema radicular, em detrimento da parte aérea. Foi o que encontraram, também, Pereira et al. (1997) em 
Tabela 4. Dados médios da relação radícula/hipocótilo das dez cultivares de feijão nos seis níveis de polietileno glicol-6000

\begin{tabular}{lcccccc}
\hline & \multicolumn{7}{c}{ Relação radícula/hipocótilo } \\
\hline \multirow{2}{*}{ Cultivares } & $\mathrm{N}_{1}$ & $\mathrm{~N}_{2}$ & $\mathrm{~N}_{3}$ & $\mathrm{~N}_{4}$ & $\mathrm{~N}_{5}$ & $\mathrm{~N}_{6}$ \\
\cline { 2 - 7 } & \multicolumn{7}{c}{ Dia em que foi feita a avaliação } \\
& $5^{\circ}$ & $8^{\circ}$ & $11^{\circ}$ & $20^{\circ}$ & $20^{\circ}$ & $20^{\circ}$ \\
\hline 1. A285 & 1,2 & 1,9 & 3,7 & 9,1 & - & - \\
2. Safira & 1,6 & 3,8 & 7,1 & 14,3 & - & - \\
3. Diamante Negro & 1,4 & 2,2 & 4,0 & 8,3 & - & - \\
4. São José & 1,6 & 2,3 & 4,8 & 10,0 & - & - \\
5. Corrente & 1,9 & 2,3 & 5,6 & 16,7 & - & - \\
6. Goytacazes & 2,0 & 2,9 & 4,8 & 7,1 & - & - \\
7. Novo Jalo & 2,2 & 5,9 & 5,6 & 16,7 & - & - \\
8. Jalo Precoce & 1,6 & 5,0 & 9,1 & 10,0 & - & - \\
9. Xamego & 1,2 & 1,8 & 4,8 & 10,0 & - & - \\
10. Onix & 1,8 & 2,4 & 2,6 & 6,2 & - & - \\
\hline
\end{tabular}

* Não houve germinação

trabalho realizado com dois genótipos de algodoeiro herbáceo; segundo os autores, a cv. CNPA Precoce 1, mais resistente ao estresse hídrico, desenvolveu menor relação R/PA (raiz/parte aérea) que a cv. CNPA 7H, menos tolerante ao déficit hídrico.

Verifica-se, ainda pelos dados da Tabela 4, haver aumento crescente da relação radícula/hipocótilo a medida em que aumenta a concentração de PEG-6000. Nunes Filho (1993) encontrou resultados semelhantes trabalhando com duas cultivares de algodoeiro em condições osmóticas diferentes, obtidas com variação dos níveis de salinidade do solo.

\section{CONCLUSÕES}

1. Em baixos potenciais osmóticos $(-0,4$ e -0,6MPa) a cultivar Diamante Negro é a mais vigorosa e a Safira a mais sensível.

2. Sob condições de estresse hídrico, durante a germinação, as radículas tendem a se desenvolver mais que o hipocótilo.

3. As plantas mais sensíveis ao estresse hídrico desenvolvem maior relação comprimento de radícula/comprimento de hipocótilo, que as mais tolerantes.

4. A metodologia do teste de vigor das plântulas não se aplica bem para os potenciais de $-0,8$ e $-1,0 \mathrm{MPa}$, induzidos por PEG-6000, necessitando-se de um número maior de sementes por repetição.

\section{REFERÊNCIAS BIBLIOGRÁFICAS}

CAMPOS, I.S.; ASSUNÇÃO, M.V. Estresse salino e hídrico na germinação e vigor do arroz. Pesquisa Agropecuária Brasileira, Brasília, v.25, n.6, p.857-862, 1990.

CARVALHO, N.M.; NAKAGAWA, J. Sementes: ciência, tecnologia e produção. 3ed. Campinas: CARGILL, 1980. $326 \mathrm{p}$.

FERNANDEZ, H.G.; JOHNSTON, B.M. The effect of water potencial on radish germination. Agricultura Tecnica, v.38, n.2, p.69-72, 1978.
FRANCO, J.A.; ESTEDAN, C.; RODRIGUEZ, C.; FERNANDEZ, J.A.; GONZALES, A. Correlación entre los efeitos di le solividad sobre el desarrolo vegetativo em semillezo y sobre le productividad de melón Galia cv. Revigal. Actas di Horticulture, n. 10, p.1418-1423, 1993. GOMES, F.P. Curso de estatística experimental. São Paulo: Nobel, 1985. 466p.

HEYDECKER, W. Vigour in viability of seeds. Chapman \& Hall, London, p.209-252,1972.

KRAMER, P.J. Plant and soil water relationships. A modern synthesis. New York: Mcgraw-Hill, 1969. 482p.

MACHADO, R.G.O.; RENA, A.R.; VIEIRA, C. Efeito da desidratação osmótica na germinação de sementes de vinte cultivares de feijão (Phaseolus vulgaris, L.). Revista Ceres, Viçosa, v.23, n.128, p.302-309, 1976.

MAGAlHÃES, A.C.; CARELLI, M.L. Germinação de sementes de feijão (Phaseolus vulgaris L.) sob condições variadas de pressão osmótica. Bragantia, Campinas, v.31, n.32, p19-26, 1972.

NUNES FILHO, J. Comportamento de duas cultivares de algodoeiro herbáceo (Gossypium hirsutum, L.r. Latifolium, Hutch) em função da salinidade e umidade do solo. Botucatu: Universidade Estadual Paulista. 1993. 96p. Tese Doutorado.

PARMER, M.Y.; MOORE, R.P. Carbowax 6000, manitol and sodium chloride for simulating drought conditions in germination studies of corn (Zea mays L.) of strong and weak vigour. Agronomy Journal, Madison, v.60, n.2, p.92-195, 1968.

PEREIRA, M.N.B.; AZEVEDO, N.C.; FERNANDES, P.D.; AMORIM NETO, M.S. Crescimento e desenvolvimento de duas cultivares de algodoeiro herbáceo em baixos níveis de umidade no solo, em casa de vegetação. Revista Brasileira de Engenharia Agrícola e Ambiental, Campina Grande, v.1, p.1-8, 1997.

POLLOCK, D.M.; ROSS, E.E. Seed and seedling vigour. In: KOZLOWSKG, T.T. Seed biology. New York: Academic Press, 1972. p.313-387.

POPINIGIS, F. Fisiologia da semente. Brasília: AGIPLAN, 1977. 289p.

PRISCO, J.T.; O'LEARY, J.W. Osmotic and "toxic" effects of salinity on germination of (Phaseolus vulgaris L.) seeds. Turrialba, v.20, p.177-184, 1970.

SINGH, K.P.; SINGH, K. Stress physiological studies on seed germination and seedling growth in maize composites. Acta Bot. Ind., v.9, p. 141-143, 1981.

SINGH, K.P.; SINGH, K. Stress physiological studies on seed germination and seedling growth of some wheat hybrids. Indian Journal of Plant Physiology, v.25, n.2, p.180-186, 1982.

SLAYTER, R.O. Physiological significance of internal water relations to crops yield. In: CASTIN, J.D.; HASKINS, F.A.; SULLIVAN, C.Y. Physiological aspects of crop yield. Wisconsin: American Society of Agronomy, 1969. p.53-83 SNEDECOR, G.W.; COCHRAN, W.G. Statistical methods. Ames: Iowa State College, 1974. 593p.

VIEIRA, R.D.; CARVALHO, N.M. de. Testes de vigor em sementes. Jaboticabal: FUNEP, 1994. 164p.

VILLELA, F.A.; DONI FILHO, L.; SIQUEIRA, E.L. Tabela de potencial osmótico em função da concentração de polietileno glicol 6000 e da temperatura. Pesquisa Agropecuária Brasileira, Brasília, v.26, n.11/12, p.1957-1968, 1991 